\title{
Antibody Functionalized Carnauba Wax Nanoparticles to Target Breast Cancer Cells
}

Banu Iyisan ${ }^{a, b}$, Johanna Simon ${ }^{a, c}$, Yuri Avlasevich ${ }^{a}$,Stanislav Baluscheve,d, Volker Mailaender ${ }^{a, c}$, Katharina Landfester ${ }^{a}{ }^{*}$

${ }^{a}$ Max Planck Institute for Polymer Research, Ackermannweg 10, 55128 Mainz, Germany

${ }^{\text {b} B o g ̆ a z i c ̧ i ~ U n i v e r s i t y, ~ I n s t i t u t e ~ o f ~ B i o m e d i c a l ~ E n g i n e e r i n g, ~} 34684$ Çengelköy, Istanbul, Turkey

${ }^{\mathrm{c} D e r m a t o l o g y}$ Clinic, University Medical Center of the Johannes Gutenberg-University Mainz, Langenbeckstr. 1, 55131 Mainz, Germany

'University of Sofia “Saint Kliment Ohridski”, Faculty of Physics, James Bourchier 5, 1164 Sofia, Bulgaria

*Address correspondence to landfester@mpip-mainz.mpg.de 

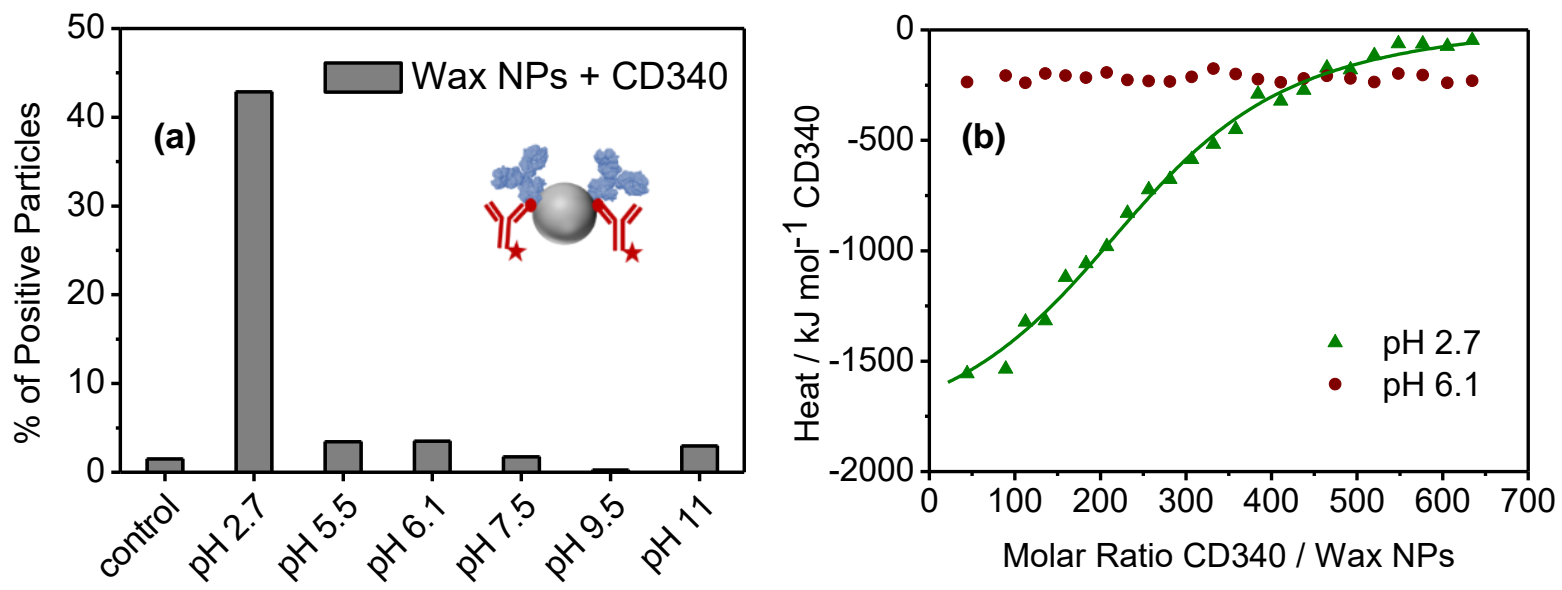

Figure S1. Antibody - functionalization of carnauba wax nanoparticles using $\mathrm{pH}$ dependent adsorption method. (a) Flow cytometry results showing the optimum adsorption at $\mathrm{pH} 2.7$ - inset: nanoparticles adsorbed with primary CD340 antibodies (blue) and secondary Alexa Fluor 405 labelled antibodies (red) used to detect the primary adsorbed CD340. (b) Adsorption isotherms of CD340 antibodies titrated into the carnauba wax nanoparticles at $\mathrm{pH} 2.7$ (green triangles) and $\mathrm{pH}$ 6.1 (red circles), $T=25{ }^{\circ} \mathrm{C}$ acquired from isothermal titration calorimetry (ITC) measurements. Isotherm at $\mathrm{pH} 2.7$ was fitted according to independent binding model represented by solid lines. 


\begin{tabular}{|c|c|c|c|c|}
\hline \multirow{2}{*}{$\begin{array}{c}\text { (a) } \\
\text { Stability Check }\end{array}$} & \multicolumn{2}{|c|}{ Wax NP } & \multicolumn{2}{|c|}{$\begin{array}{c}\text { Antibody-functionalized } \\
\text { Wax NP }\end{array}$} \\
\hline & $t=0$ & $\mathrm{t}=6$ months & $t=0$ & $\mathrm{t}=6$ months \\
\hline $\begin{array}{l}\text { Zeta Potential } \\
(\mathrm{mV})\end{array}$ & $-21.2 \pm 0.2$ & $-21.3 \pm 0.5$ & $-8.1 \pm 0.2$ & $-8.9 \pm 0.8$ \\
\hline
\end{tabular}

(b) Antibody functionalized Carnauba Wax NPs at $\mathrm{t}=\mathbf{0}$

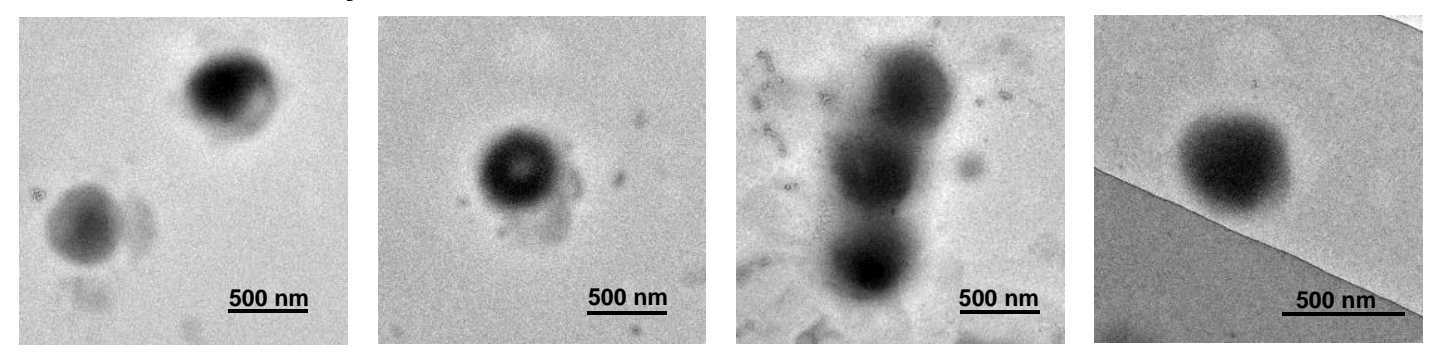

(c) Antibody functionalized Carnauba Wax NPs at $t=6$ months
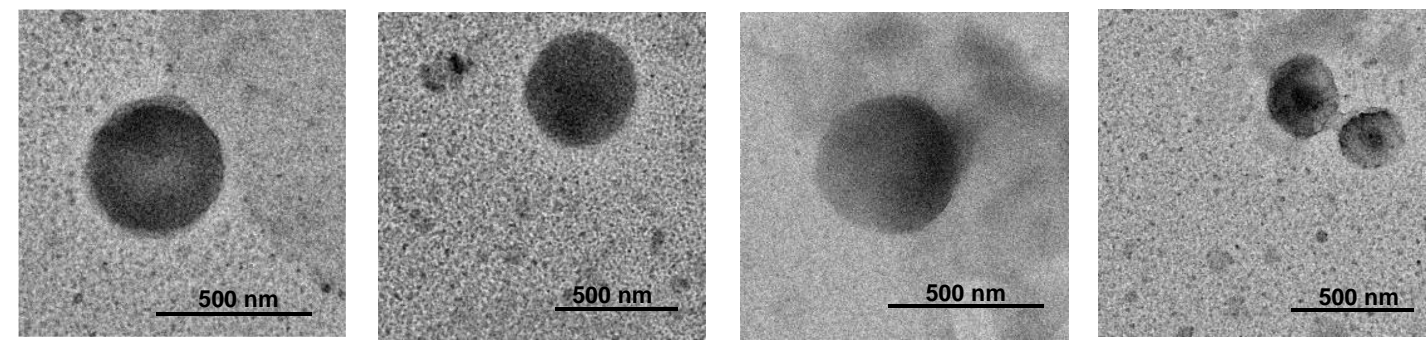

(d)

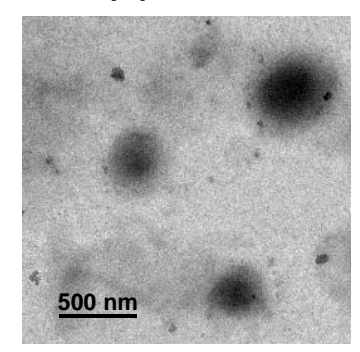

Carnauba Wax NPs $-t=6$ months
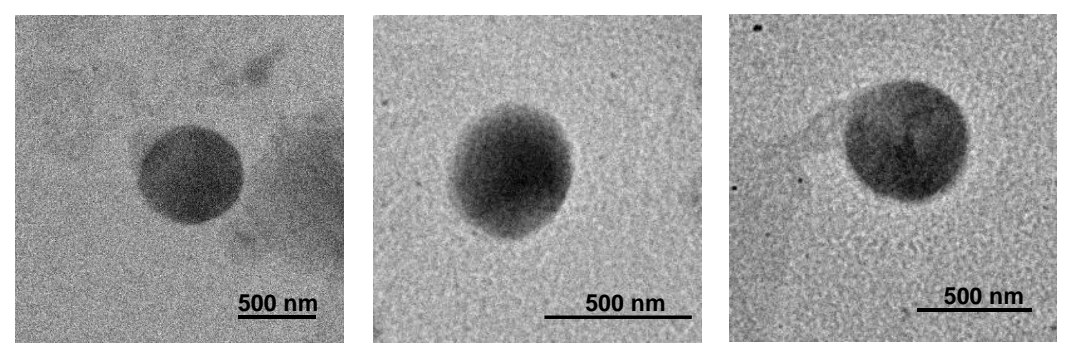

Figure S2. Long term physicochemical stability. (a) Zeta potential values before and after antibody functionalization of carnauba wax nanoparticle proved the integrity within 6 months period of storage at $4{ }^{\circ} \mathrm{C}$. TEM micrographs of antibody functionalized carnauba wax nanoparticles (b) at initial state and (c) after 6 months of storage. (d) TEM micrographs of naked carnauba wax nanoparticles after 6 months of storage period 


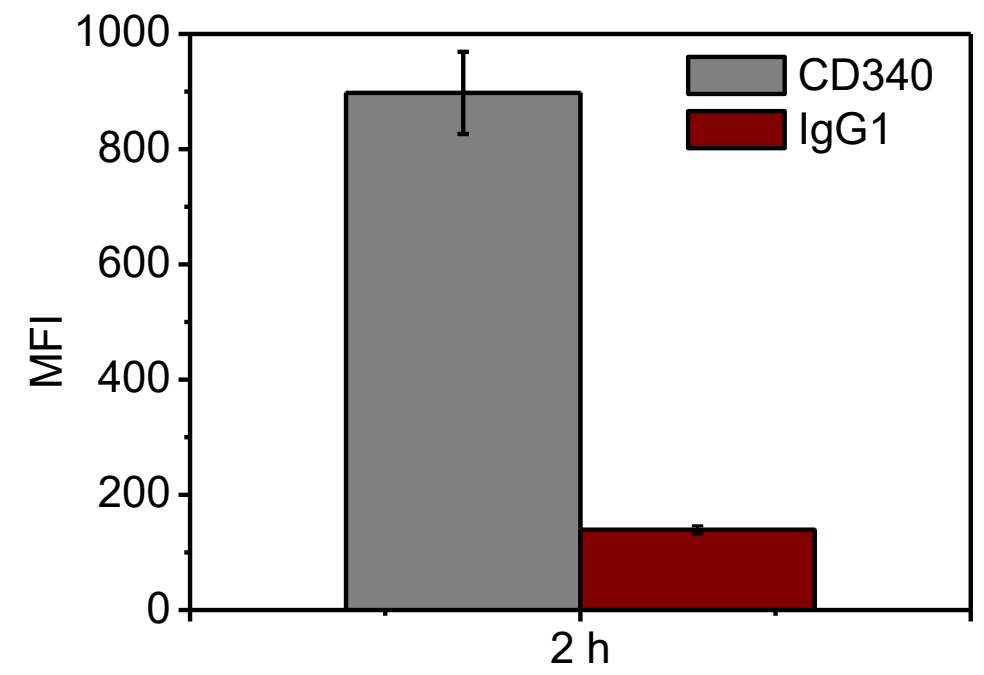

Figure S3. Long Term Biological Function. Cellular uptake of antibody functionalized carnauba wax nanoparticles towards BT474 HER2-positive breast cancer cells after 6 months storage at $4{ }^{\circ} \mathrm{C}$. Concentration of NPs is $75 \mu \mathrm{g} \mathrm{mL}^{-1}$. HER2 $=$ Human epidermal growth receptor $2, \mathrm{MFI}=$ median fluorescence intensity. 


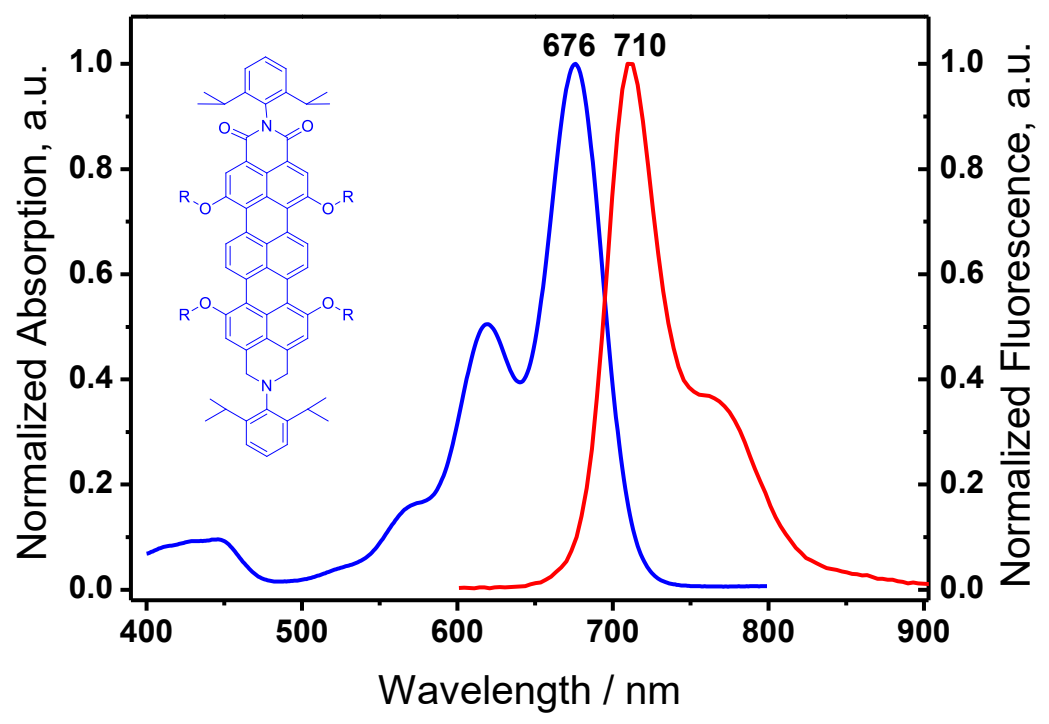

Figure S4. Absorption (red lines) and fluorescence emission spectra (blue lines) of tetraphenoxyTDI (N,N'-(2,6-diisopropylphenyl)-1,6,9,13-tetra[4-(1,1,3,3-tetramethylbutyl)- phenoxy] terrylene-3,4,11,12-tetracarboxidiimide). $\mathrm{R}=(4$-tert-octylphenoxy)

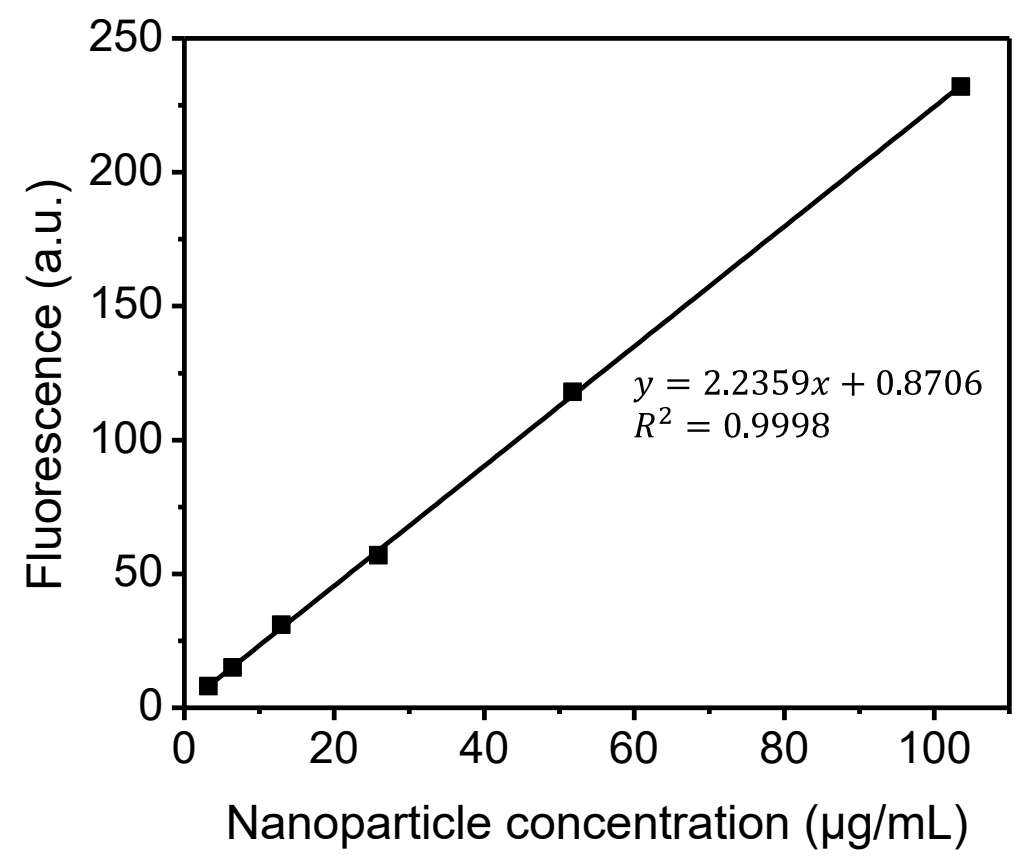

Figure S5. Calibration curve used for the determination of the nanoparticle concentration for the antibody-functionalized nanoparticles. 

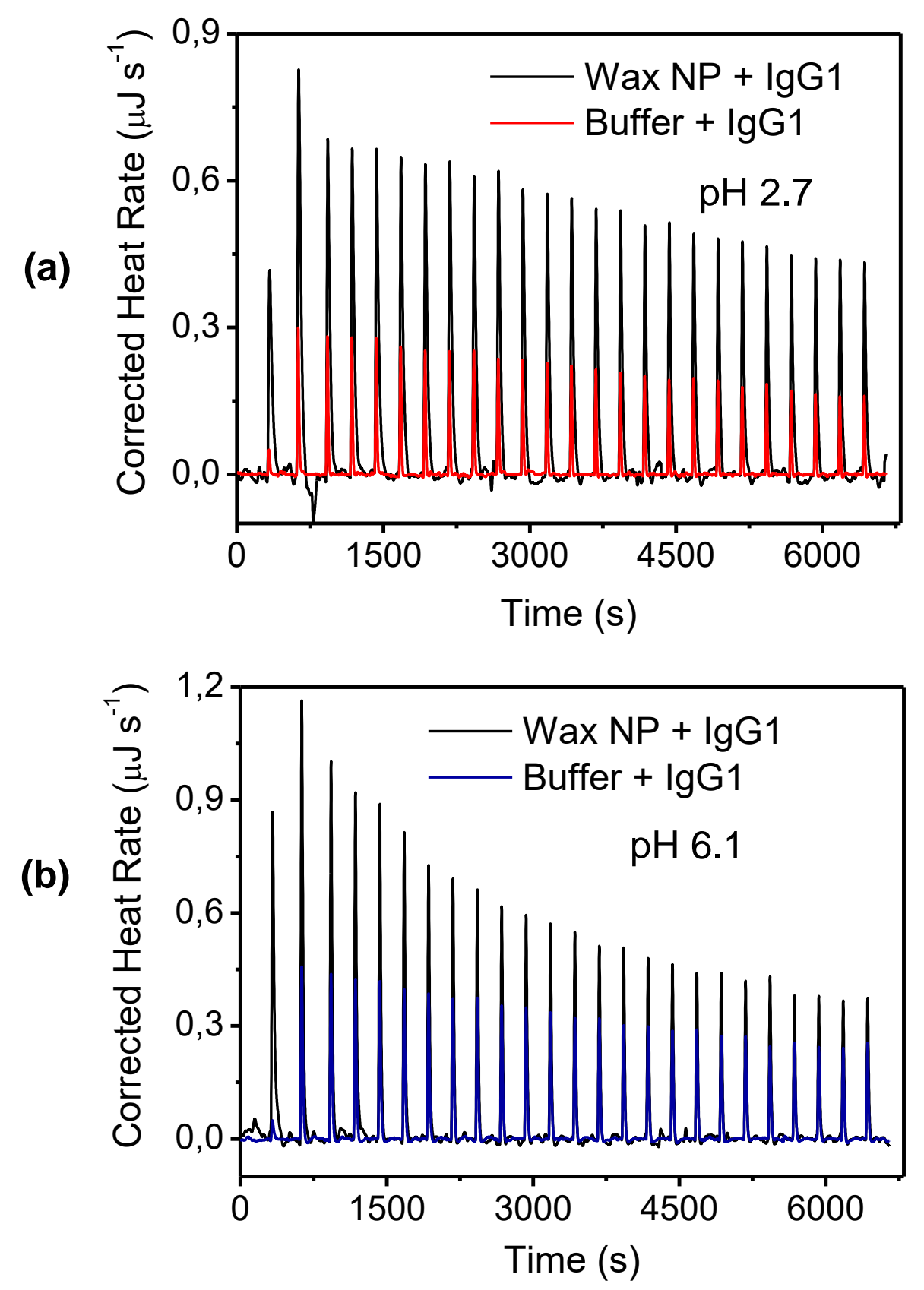

Figure S6. ITC raw heat rates for antibody-modification of carnauba wax nanoparticles at (a) pH 2.7 and (b) at $\mathrm{pH} 6.1$ 